\title{
Evaluation of minimally invasive laser ablation in children with osteoid osteoma
}

\author{
HAO WU ${ }^{1-4}, \mathrm{CHENG} \mathrm{LU}^{1-4}$ and MING CHEN ${ }^{1-4}$ \\ ${ }^{1}$ Department of Orthopedics, Xuzhou Central Hospital; ${ }^{2}$ Department of Orthopedics, The Affiliated \\ XuZhou Hospital of Medical College of Southeast University; ${ }^{3}$ Department of Orthopedics, Xuzhou \\ Clinical School of Xuzhou Medical College; ${ }^{4}$ Department of Orthopedics, Xuzhou Clinical Medical \\ College of Nanjing University of Chinese Medicine, Xuzhou, Jiangsu 221009, P.R. China
}

Received May 17, 2016; Accepted November 2, 2016

DOI: $10.3892 / \mathrm{ol} .2016 .5417$

\begin{abstract}
The effects between minimally invasive percutaneous laser ablation and open surgery in the treatment of children with osteoid osteoma were compared in the present study. A total of 72 cases of children with osteoid osteoma were divided into control and observational groups, containing 36 cases in each group. The control group underwent conventional open surgery while the observational group underwent minimally invasive CT guided percutaneous laser ablation. Effects of both operations were compared. The operation duration, blood loss and plaster fixation duration of the observational group were significantly less than those of the control group. The postoperative pain score (VAS) at 1 day and 7 days were significantly lower than that of the control group, the differences were statistically significant $(\mathrm{P}<0.05)$. The lesion resection rate, effective rate of bone hyperplasia, effective rate of swelling and effusion and total effective rate of the observational group were significantly higher than those of the control group, the differences were statistically significant $(\mathrm{P}<0.05)$. Incidence of adverse reactions of observational group was significantly lower $(\mathrm{P}<0.05)$ than that of the control group. However, the difference was not significant when comparing 1 -year recurrence rate for the two groups. The minimally invasive percutaneous laser ablation has better surgery effects compared with open surgery in the treatment of children with osteoid osteoma.
\end{abstract}

\section{Introduction}

Osteoid osteoma of children is a benign ostogenic tumor, which mostly causes pain at night, and easily occurs at the

Correspondence to: Dr Hao Wu, Department of Orthopedics, The Affiliated XuZhou Hospital of Medical College of Southeast University, 199 South Jiefang Road, Xuzhou, Jiangsu 221009, P.R. China

E-mail: ligd315963355@163.com

Key words: minimally invasive percutaneous laser ablation, osteoid osteoma of children, effective rate, recurrence rate weight-bearing bone, especially femur and tibia. Accounting for $50 \%$ of the cases (1), osteoid osteoma is self-limiting and will gradually ease with the application of non-steroidal anti-inflammatory drugs or symptoms lasting for 5 years (2). However, for children in development, osteoid osteoma can lead to athletic dysfunction, muscular dystrophy and skeletal dysplasia of the affected limb (3).

Surgical resection remains the main method of treatment of osteoid osteoma (4). Due to the small volume of the tumor nests, obvious surrounding bone hyperplasia, and many tumors are still in the cortex, the surgery location it difficult as well as vascular and nerve injuries are at high risk. Indeed, extensive resection or recurrence, because of the incomplete resection can lead to the difficulty of obtaining satisfactory tissue specimens for pathological diagnosis (5). Accordingly, bone defect would last for a long time after wide excision and fixed protection is necessary, increasing the risk of pathological fracture (6). However, percutaneous minimally invasive laser ablation guided by CT may improve the positioning accuracy, with the advantages of light damage, fast recovery, and complete treatment (7).

This method has been applied in clinical practice and we conducted the present study to compare and analyze the difference between minimally invasive percutaneous laser ablation and open surgery in our center to provide reference for clinical treatment.

\section{Patients and methods}

Patients. The protocol of the current study was approved by the Ethics Committee Xuzhou Central Hospital (Jiangsu, China). Guardians were informed regarding the rights of children and written consent was obtained. The selected patients were examined by X-ray, CT or MRI. They shared similar features including roundness, low density shadow, seen in the bone cortex; lesion diameter, generally within $1.5 \mathrm{~cm}$; spot high density shadow in the central lesion; the border lesion, still clear and bone sclerosis around the lesion that was obviously part of the local periosteal reaction and surrounding soft tissue swelling. CT mainly manifested soft tissue density tumor nests similar to roundness with smooth edge in the bone sclerosis area. There were small calcifications in tumor nests. 
Some adjacent soft tissues, close to the tumor had significant swelling with effusion. The body of the tumor was intensified significantly with enhanced scanning. MRI mainly manifested TI weighted low image, medium signal, T2 weighted image was low, medium or high signal. The calcification inside the tumor nest had a low signal. Notably, trauma, developmental deformities and patients not suitable for surgical treatment were excluded from the study.

A total of 72 cases of children with osteoid osteoma diagnosed at the Xuzhou Central Hospital from January, 2013 to January, 2016 were continuously selected. Selected patients were then divided into a control group and an observational group. Each group comprised 36 cases according to the method of treatment. The control group comprised 24 cases of boys and 13 cases of girls. The children were aged 3-16 years (average, 10.5 \pm 4.6 years), with a disease duration of 1-5 months (average, $2.2 \pm 1.3$ months), and a maximum lesion diameter of $0.4-1.3 \mathrm{~cm}$ (average, $0.8 \pm 0.3 \mathrm{~cm}$ ). The lesions were located in the proximal femur in 20 cases ( 6 cases in the femoral trochanter and neck, 6 cases in tibia, 2 cases in ilium, 1 case in calcaneus, 1 case in ischia) and 22 patients who suffered from aching (with 6 cases of dysfunction, including instability of gait, walking claudication, joint activity limitation). A total of 3 cases had an affected limb shorter than the contralateral limb in development.

The observational group included 22 boys and 14 girls, aged 3.5-15 years (average, 10.2 \pm 4.5 years), with a duration of 1.5-5 months (average, 2.6 \pm 1.5 months), and a maximum lesion diameter of $0.5-1.4 \mathrm{~cm}$ (average, $0.7 \pm 0.4 \mathrm{~cm}$ ). Lesions were located in the proximal femur in 22 cases $(6$ cases in the femoral trochanter and neck, 5 cases in tibia, 1 case in ilium, 1 case in calcaneus, 1 case in ischia) and 20 patients who suffered from aching with 8 cases of dysfunction, including instability of gait, walking claudication, and joint activity limitation. Four cases had an affected limb shorter than the contralateral limb in development. Baseline data in the two groups were comparable.

Research methods. The control group underwent conventional open surgery. The surgical approach selected included Smith-Peterson or Ludloff approach according to lesion position. The local part was located by Kirschner and confirmed by CT. Abrasive drilling and open windows, cortical bone and bone proliferative response were partially completely cut off. Samples were sent to pathological examination.

Observational group was treated with minimally invasive CT guided percutaneous laser ablation using (Siemens, Erlangen, Germany) 64-slice spiral CT machine, tube voltage was $120 \mathrm{kV}$, tube current was $60 \mathrm{~mA}, 1.2$ screw pitch, slice thickness was $5.0 \mathrm{~mm}$ and spacing was $2.5 \mathrm{~mm}$ ). PinPoint laser navigation piercing system (Philips, Eindhoven, The Netherlands), a trocar was 18 G Chiba, Diomed laser generator, GaAlAs semiconductor laser (maximum power $15 \mathrm{~W}$, wavelength $810 \mathrm{~nm}$, ambient air cooling). SMA-905 standard connector linked laser fiber guide wire $(0.4-1.0 \mathrm{~mm})$, with the forming 'BU' type t-branch pipe matched with guide wire. Patients were examined with CT or MR before operation to ensure the lesion location, major organs and tissues around, especially the distribution and running route of the nerves, and blood vessels. Anesthesia, in supine position, CT scan entered into the PinPoint navigation system program. The scanned image was placed into the simulated navigation. The mobile manipulators arm and simulated puncture point and angle according to emitted laser of the manipulator arm. Simulation to measure the puncture depth with three-dimensional reconstruction of computer software was obtained. The guide wire was linked to the generator. The turning out of the generator and the end of the guide wire emitted dazzling laser and the overflow of the whole guide wire was carefully observed. When the trocar punctured the appropriate place, the needle core was removed and laser guide wire was set into the dedicated t-branch pipe of laser guide wire and fixed. The trocar import and the pinpoint was exposed about $5 \mathrm{~mm}$, and finally $10 \mathrm{ml}$ empty needle was connected to side tube of the t-branch pipe. The laser ablation process emitting power was 6-8 $\mathrm{W}$ in continuous pulse. Ablation time was selected according to the diameter of the tumor nest. When the tumor diameter was $<9 \mathrm{~mm}$, the estimated time of ablation was $3.5 \mathrm{~min}$ while, when the diameter was $9-11 \mathrm{~mm}$, the estimated time of ablation was $4 \mathrm{~min}$, and when the diameter was $>11 \mathrm{~mm}$, the estimated time of ablation was $45 \mathrm{~min}$. Prostration was recommended for $24 \mathrm{~h}$, avoiding strenuous exercise.

Observation index. The following values were compared: The operation duration intraoperative blood loss, postoperative pain score (VAS), plaster fixation time, lesion resection rate, effective rate of treatment, adverse reaction and the rate of recurrence. Routine follow-up was conducted postoperatively at 1 week, 1 month, 3 months, 6 and 12 months. CT examined the general conditions of the tumor nests, sclerotin and the surrounding soft tissue. The judgment standards of effective treatment were that nidus volume decreased or disappeared. The original bone hyperplasia area shrunk or disappeared, normal sclerotin and bone trabecula recovery were visible in original hyper osteogeny and osteosclerosis area. Periosteal reaction disappeared, surrounding soft tissue swelling and effusion was relieved or disappeared. Adverse reactions included infection, injury of nerve, muscle or vascular non-ideal recovery of limb function.

Statistical methods. Using SPSS 20.0 (IBM SPSS, Armonk, NY, USA) software for statistical analysis, measurement data were expressed as mean \pm standard deviation, $t$-test was applied in comparisons between the two groups, data were expressed as cases or percentage (corrected) and the $\chi^{2}$ test was applied for comparisons between two groups. $\mathrm{P}<0.05$ was considered to indicate a statistically significant difference.

\section{Results}

Comparison of surgical indexes. The operation time, intraoperative blood loss, gypsum fixation time in the observational group were significantly lower $(\mathrm{P}<0.05)$ than those in the control group. The VAS of postoperative day 1 and day 7 in observational group was significantly lower $(\mathrm{P}<0.05)$ than that in the control group (Table I).

Comparison of lesion resection rate and effective rate of treatment. The resection rate, effective rate of bone hyperplasia, 
Table I. Comparison of surgical indexes.

\begin{tabular}{lccccccc}
\hline & & & & & & VAS \\
\cline { 5 - 7 } Groups & $\begin{array}{c}\text { Operation } \\
\text { duration (min) }\end{array}$ & $\begin{array}{c}\text { Intraoperative } \\
\text { blood loss (ml) }\end{array}$ & $\begin{array}{c}\text { Gypsum fixation } \\
\text { duration (days) }\end{array}$ & Preoperative & $\begin{array}{c}\text { Postoperative } \\
\text { day 1 }\end{array}$ & $\begin{array}{c}\text { Postoperative } \\
\text { day } 7\end{array}$ \\
\hline Control & $72.4 \pm 13.3$ & $213.5 \pm 34.7$ & $6.8 \pm 1.3$ & $3.2 \pm 0.7$ & $4.5 \pm 1.2$ & $2.2 \pm 0.6$ \\
Observation & $46.8 \pm 12.2$ & $64.9 \pm 21.6$ & $2.6 \pm 1.0$ & $3.3 \pm 0.6$ & $2.1 \pm 0.4$ & $0.3 \pm 0.1$ \\
t-test & 4.968 & 6.532 & 5.120 & 0.322 & 6.127 & 5.857 \\
P-value & 0.036 & 0.014 & 0.033 & 0.864 & 0.021 & 0.025 \\
\hline
\end{tabular}

VAS, postoperative pain score.

Table II. Comparison of lesion resection rate and effective rate of treatment [case (\%)].

\begin{tabular}{|c|c|c|c|c|c|c|}
\hline Groups & Cases & $\begin{array}{l}\text { Lesion } \\
\text { resection rate }\end{array}$ & $\begin{array}{l}\text { Effective rate of } \\
\text { tumor nest volume }\end{array}$ & $\begin{array}{l}\text { Effective rate of } \\
\text { bone hyperplasia }\end{array}$ & $\begin{array}{c}\text { Effective rate of } \\
\text { swelling and effusion }\end{array}$ & $\begin{array}{c}\text { Total } \\
\text { effective rate }\end{array}$ \\
\hline Control & 36 & $26(72.2)$ & 33 (91.7) & $23(63.9)$ & $25(69.4)$ & $22(61.1)$ \\
\hline Observational & 36 & 33 (91.7) & 35 (97.2) & $32(88.9)$ & 33 (91.7) & 34 (94.4) \\
\hline$\chi^{2}$ & & 4.600 & 0.265 & 6.237 & 5.675 & 11.571 \\
\hline P-value & & 0.032 & 0.607 & 0.013 & 0.017 & 0.001 \\
\hline
\end{tabular}

Table III. Comparison of adverse reactions and recurrence rate [case (\%)].

\begin{tabular}{lccccc}
\hline Groups & Cases & Infection & $\begin{array}{c}\text { Injury of nerves, } \\
\text { mules, blood vessels }\end{array}$ & $\begin{array}{c}\text { Non-ideal recovery } \\
\text { of limb function }\end{array}$ & $\begin{array}{c}\text { The adverse } \\
\text { reaction rate }\end{array}$ \\
\hline Control & 36 & $3(8.3)$ & $3(8.3)$ & $4(11.1)$ & $10(27.8)$ \\
Observational & 36 & $1(2.8)$ & $1(2.8)$ & $1(2.8)$ & $3(8.3)$ \\
$\chi^{2}$ & & & & 4.600 & 0.265 \\
P-value & & & & 0.032 & 0.607 \\
\hline
\end{tabular}

effective rate of swelling and effusion, and the total effective rate of the observational group were significantly higher $(\mathrm{P}<0.05)$ than those of the control group (Table II).

Comparison of adverse reactions and recurrence rate. The adverse reaction rate of the observational group was significant $(\mathrm{P}<0.05)$ compared to that of the control group (Table III). However, one year recurrence rate comparison of the two groups was similar (Table III).

\section{Discussion}

Percutaneous laser ablation involves tissue degeneration, coagulation, vaporization and necrosis through the heat produced by pressure, photochemical and electromagnetic effects after the tissue absorbed the laser (8). At present, this technique is widely used in thyroid nodule, liver cancer, renal cell carcinoma and other diseases (9).

Our experience of laser ablation in the treatment of osteoid osteoma is described. Continuous ablation time should not last extremely long. The study shows that when the ablation center vaporized to the coking zone the conduction of heat to the surrounding was limited. Thus, it should be less vaporized to the coking zone, and increased in coagulation necrosis zone (10). Segmented ablation was used and a small amount of liquid was injected during this period. Overflow of some smoke or a burnt smell in the trocar during the ablation process was considered an indication of vaporization in the zone of the range of ablation. In these cases, the ablation was suspended and the laser guidewire was removed. Careful observation was made to see whether or not the coking tissue adhered to the wire tip. If there was obvious coking adhesion on the tip, the adhesion was cut off with sterile blade and the guide wire guiding light was retested property. At the same time, the waste gas was immediately extracted. Then, a small amount of lidocaine or normal saline was injected the the ablation operation was repeated.

The trocar was punctured to the distal end of the lesion, and a small amount of rotation was done to form a channel in the tumor body, which was beneficial for the guide wire 
to enter. Leakage length of guide wire through the trocar tip should not be too long or too short (11). A depth that was extremely long would affect the ablation effect of the proximal end of the lesion, whereas a length that was extremely short would, not only affect ablation of the distal end of the lesion, but also mistakenly heat the tube thereby causing skin and muscle burn (12). The general import length was $3-5 \mathrm{~cm}$, the distance was appropriately extended if the diameter was larger. Ablation order generally used the distal end of the first lesion and the proximal end of the following lesion. The selection of the mode of treatment was also very important. There were three methods of $0.7 \mathrm{sec}$ radiation- $0.3 \mathrm{sec}$ interval, $0.8 \mathrm{sec}$ radiation- $0.2 \mathrm{sec}$ interval, $0.9 \mathrm{sec}$ radiation- $0.1 \mathrm{sec}$ interval models (13). In our study, the operation time, blood loss, gypsum fixed time in the observational group were significantly less than those of the control group. The VAS of the postoperative day 1 and day 7 were significantly lower than that of the control group. The rate of lesion resection, the effective rate of bone hyperplasia, the swelling and effusion of the observational group were significantly higher than those of the control group. The incidence of adverse reactions of the observational group was lower than that of the control group. There was statistically significant difference when comparing the groups after the first year recurrence rate. Our results indicated that the minimal invasive percutaneous laser ablation had better effects compared with open surgery in the treatment of children with bone osteoid osteoma.

Limitations of our study are the small number of our samples and the short duration of the follow-up. Indeed, the effects of the treatment of children with osteoid osteoma may be different in different parts, minimally invasive laser with CT guidance can improve the positioning accuracy of the lesions. CT guidance can also improve the open surgical resection scope of the lesion, reduce the incidence of hyper osteogeny and surrounding tissue swelling, as well as other complications (14). In addition, the percutaneous radiofrequency ablation has also important application value in the treatment of osteoid osteoma in children (15). Thus, additional large number of samples, randomized controlled clinical trial should still be conducted to further discuss the safety, effectiveness, indications of osteoid osteoma with minimally invasive operation.

\section{References}

1. Agrawal P and Sobti A: A Brodie's abscess of femoral neck mimicking osteoid osteoma: Diagnostic approach and management strategy. Ethiop J Health Sci 26: 81-84, 2016.

2. Aiba H, Hayashi K, Inatani H, Satoshi Y, Watanabe N, Sakurai H, Tsuchiya $\mathrm{H}$ and Otsuka T: Conservative treatment for patients with osteoid osteoma: A case series. Anticancer Res 34: 3721-3725, 2014.

3. Athwal P and Stock H: Osteoid osteoma: A pictorial review. Conn Med 78: 233-235, 2014.

4. Kaiser MS, Rahman W, Hossain M, Siddiquee TH, Hossain MT, Das KP, Islam MS and Datta NK: Evaluation of outcome of surgical excision of the nidus of osteoid osteoma of long bone. Mymensingh Med J 23: 686-694, 2014.

5. Yokouchi M, Nagano S, Shimada H, Nakamura S, Setoguchi T, Kawamura I, Ishidou Y and Komiya S: Early complete remission of osteoid osteoma with conservative medical management. Pediatr Rep 6: 5311, 2014.

6. Font Segura J, Barrera-Ochoa S, Gargallo-Margarit A, Correa-Vázquez E, Isart-Torruella A and Mir Bullo X: Osteoid osteoma of the distal humerus mimicking sequela of pediatric supracondylar fracture: Arthroscopic resection - case report and a literature review. Case Rep Med 2013: 247328, 2013.

7. Fuchs S, Gebauer B, Stelter L, Schäfer ML, Renz DM, Melcher I, Schaser K, Hamm B and Streitparth F: Postinterventional MRI findings following MRI-guided laser ablation of osteoid osteoma. Eur J Radiol 83: 696-702, 2014.

8. Kaul D, Bonhomme O, Schwabe P, Gebauer B and Streitparth F: Osteoid osteoma with a multicentric nidus: Interstitial laser ablation under MRI guidance. Case Rep Orthop 2013: 254825, 2013.

9. Li D, Kang J and Madoff DC: Locally ablative therapies for primary and metastatic liver cancer. Expert Rev Anticancer Ther 14: 931-945, 2014.

10. Maurer MH, Gebauer B, Wieners G, De Bucourt M, Renz DM, Hamm B and Streitparth F: Treatment of osteoid osteoma using CT-guided radiofrequency ablation versus MR-guided laser ablation: A cost comparison. Eur J Radiol 81: e1002-e1006, 2012.

11. Martel J, Bueno A, Nieto-Morales ML and Ortiz EJ: Osteoid osteoma of the spine: CT-guided monopolar radiofrequency ablation. Eur J Radiol 71: 564-569, 2009.

12. Zouari L, Bousson V, Hamzé B, Roulot E, Roqueplan F and Laredo JD: CT-guided percutaneous laser photocoagulation of osteoid osteomas of the hands and feet. Eur Radiol 18: 2635-2641, 2008.

13. DeFriend DE, Smith SP and Hughes PM: Percutaneous laser photocoagulation of osteoid osteomas under CT guidance. Clin Radiol 58: 222-226, 2003.

14. Ramseier LE, Duc S and Exner GU: Osteoid osteoma. CT guided drilling and radiofrequency ablation. Orthopade 35: 989-992, 2006 (In German).

15. Ruiz Santiago F, Castellano García MdelM, Guzmán Álvarez L, Martínez Montes JL, Ruiz García M and Tristán Fernández JM: Percutaneous treatment of bone tumors by radiofrequency thermal ablation. Eur J Radiol 77: 156-163, 2011. 